\title{
Diferenças entre a defesa pública e privada: como elas afetam a condenação no processo de tráfico de drogas?
}

\section{Differences between public and private advocacy: how they affect conviction in the drug trafficking procedure?}

\author{
Ana Rita Nascimento (Crisp/ UFMG) ${ }^{1}$ \\ Livia Lages (Crisp/ UFMG) ${ }^{2}$ \\ Daniely Reis (Crisp/ UFMG) \\ Juliana Neves (CRISP/UFMG) ${ }^{4}$
}

\section{RESUMO}

A presença de um defensor é obrigatória para a viabilização do processo penal, isso porque um dos fundamentos do devido processo é o direito à ampla defesa do réu. Não existe processo penal se não existir defesa. Portanto, compreender o papel do defensor - público ou particular - é primordial para entender o curso do processo penal. Então, esse trabalho, a partir da análise de processos finalizados durante o período de 2007 a 2017, em Belo Horizonte, Minas Gerais Brasil, propõe-se a investigar as diferenças entre a defesa particular e pública e refletir sobre qual é a relevância dessa distinção para o processo de tráfico de drogas. No que tange aos resultados, não foi encontrada diferença estatisticamente significativa entre as defesas exercidas por advogado particular ou por defensor público, tanto no que se refere ao transcurso do processo, quanto ao resultado final alcançado na sentença. Em nossa interpretação, isso ocorre porque o sujeito, quando indiciado por tráfico, já é previamente julgado como desviante, sendo os argumentos da defesa incapazes de alterar essa percepção da família judicial.

\section{PALAVRAS-CHAVE:}

Processo de tráfico de drogas; defesa; defensor público; advogado particular; Sistema de Justiça Criminal.

\footnotetext{
${ }^{1}$ Graduanda em Direito pela Universidade Federal de Minas Gerais (UFMG) e pesquisadora do Centro de Estudos de Criminalidade e Segurança Pública (Crisp/UFMG)

${ }^{2}$ Mestre em Sociologia pela Universidade Federal de Minas Gerais (UFMG) e pesquisadora do Centro de Estudos de Criminalidade e Segurança Pública (Crisp/UFMG)

${ }^{3}$ Mestre em Sociologia pela Universidade Federal de Minas Gerais (UFMG) e pesquisadora do Centro de Estudos de Criminalidade e Segurança Pública (Crisp/UFMG)

${ }^{4}$ Doutora em Sociologia pela Universidade Federal de Minas Gerais (UFMG) e pesquisadora do Centro de Estudos de Criminalidade e Segurança Pública (Crisp/UFMG)
} 


\begin{abstract}
The presence of an defense attorney is mandatory for the criminal procedure, since one of it's legal grounds is the right to defense. Therefore, comprehending the role of the defense attorney - public or private - is essential to understand the course of criminal procedures. Thus, based on the analysis of processes completed during the period from 2007 to 2017 in Belo Horizonte, Minas Gerais -Brazil, this paper aims to investigate the differences between private and public legal defense and to define the relevance of this distinction in the realm of drug trafficking procedure. Regarding the results, no statistically significant difference was found between legal defenses exercised by a private lawyer or public defender, both in the course of the procedure or in the sentencing. In our view, this result indicates that the suspect, when accused for drug trafficking, is previously judged as a deviant, and the defense arguments are unable to change this perception of the judicial body.
\end{abstract}

\title{
KEYWORDS:
}

Drug trafficking procedure; defense; public attorney; lawyer; Criminal Justice System.

\section{INTRODUÇÃO}

"Sem advogado não há justiça e sem justiça não há democracia” (PAIVA, 1999). Assim é reconhecido o papel da advocacia: uma forma de garantir os direitos e interesses dos cidadãos perante o Estado. O advogado é popularmente visto como o herói que confronta juízes e promotores, a fim de defender o seu cliente. Atestando o quanto essa profissão é significativa, os cristãos elegem Jesus como seu advogado divino (PAIVA, 1999). A advocacia surgiu junto com a democracia, em Atenas, onde já havia figuras de grandes oradores designados para defender os mais pobres dos poderosos (ORIGEM, 2015). Foi em Roma, base da nossa tradição judicial, onde, durante o império de Justino, nasceu a primeira Ordem de Advogados no Império Romano do Oriente, reconhecendo a profissão e tornando-a organizada (LÔBO, 2017).

No Brasil, a advocacia foi inicialmente exercida por profissionais formados em Portugal, conforme as Ordenações Filipinas e, posteriormente, graças à criação dos primeiros cursos de direito de Olinda e São Paulo, em 1827, a advocacia tornou-se uma profissão reconhecida pelos brasileiros (LÔBO, 2017). Em 1930, durante o governo de Getúlio Vargas, foi criada a Ordem dos Advogados do Brasil (CUNHA, 2005), órgão responsável pela 
organização e defesa dos interesses dessa classe de profissionais. Entretanto, ela somente alcançava uma clientela que podia arcar com o preço dos honorários. Foi somente com a Constituição de 1988, com a criação da Defensoria Pública, que os desfavorecidos economicamente tiveram acesso à defesa gratuita, enquanto um direito a ser resguardado por uma instituição com essa função precípua (CUNHA, 2005). Até então, a assistência judiciária gratuita era uma das atribuições do Ministério Público (MOREIRA, 2017).

A Constituição da República (CR/88) estabelece que a advocacia e a Defensoria Pública são essenciais à administração da justiça e fundamental para o regime democrático, pois é o exercício da defesa e do contraditório que impedem a prática de abusos por parte do Estado. Assim, sobretudo no campo da justiça criminal - que é o objeto de análise deste trabalho e o âmbito em que o Estado exerce o seu poder punitivo -, o direito à defesa se torna a garantia formal de "voz" da pessoa processada e se mostra essencial para coibir arbitrariedades. Com esse propósito, foi criada a Defensoria Pública que, além de atuar na orientação e assistência jurídica, encontra-se formalmente comprometida com os direitos humanos e com a justiça social.

Embora advogados e defensores exerçam a orientação e a defesa de réus em processos penais e sejam bacharéis em direito, há grandes diferenças entre estes profissionais: os advogados particulares recebem honorários e atuam como patronos da causa, representando os interesses de seus clientes e podem optar se atuam ou não sobre uma dada demanda, de acordo com suas perspectivas profissionais. Os defensores públicos, via de regra, não escolhem quem defender ou a causa sobre a qual lhes interessa atuar, pois são concursados e remunerados pelo Estado.

Se, por um lado, os advogados têm mais gerência sobre suas agendas, demandas e clientela, os defensores não podem negar assistência jurídica ao seu público de referência; o que pode comprometer ou dificultar a análise pormenorizada de cada caso, tendo em vista a quantidade de demanda. Por outro, é mais provável que o defensor desenvolva relações mais próximas com os demais membros da corte. É que os concursos públicos têm como características a estabilidade e lotações por comarca, o que pode favorecer o contato com o mesmo promotor e juiz.

Considerando essas diferenças, até que ponto a atuação de um advogado particular se difere, na prática, de um defensor público na defesa de réus processados por tráfico de drogas? 
É essa questão que o presente trabalho pretende responder, a partir da análise comparativa das práticas de defesa em 748 processos de tráfico de drogas que tramitaram na comarca de Belo Horizonte entre 2007 e 2017. Para a organização do texto, o próximo tópico será dedicado à discussão teórica sobre o assunto, sobretudo no que tange a contraposição entre "a lei dos livros" e a "lei na prática". Na sequência, a metodologia utilizada na pesquisa será apresentada e, a seguir, os resultados serão expostos e discutidos. Por fim, seguem as considerações finais.

\section{Poder de punir e direito à defesa: conciliação teórica ou prática?}

A possibilidade de se defender de quaisquer acusações no âmbito do Sistema de Justiça Criminal (SJC) ${ }^{5}$ é uma garantia constitucional e um limite para o exercício do poder punitivo do Estado. O processo penal é o meio pelo qual, simultaneamente, o Estado exerce seu poder de punir, servindo como instrumento para a aplicação de sanções, caso haja descumprimento das normas jurídicas, mas é também instrumento para assegurar o direito à defesa e ao contraditório, garantindo que o réu só seja punido caso haja comprovação nos autos do descumprimento de tais normas (BONFIM, 2009).

Já no primeiro artigo do Estatuto da Advocacia e da Ordem dos Advogados do Brasil $(\mathrm{OAB})^{6}$ é citado o jus postulandi, isto é, a obrigatoriedade da postulação de um advogado em juízo. Assim, não existe processo penal sem a atuação de um advogado particular ou defensor público, sendo limitados os casos em que o ordenamento jurídico faculta a ausência da defesa técnica. No que tange ao processo penal, após a denúncia, o juiz não pode dar andamento ao processo enquanto não tiver sido nomeado um defensor (público ou particular) que atue em favor do réu, evitando que este seja penalizado sem a observância de seus direitos.

Segundo o Código de Ética e Disciplina da OAB, o profissional tem o dever moral, e também legal, de defender seu cliente perante a parte contrária ${ }^{7}$. Porém, será mesmo que isso sempre acontece? Quais são as barreiras que dificultam o exercício da defesa pública e privada? Na literatura, há uma carência de dados consolidados sobre a atuação da defesa, bem como

\footnotetext{
${ }^{5}$ O SJC é aqui considerado como a articulação de atores institucionais, que envolve a Polícia Militar, Polícia Civil, Ministério Público, Judiciário e estabelecimentos prisionais.

6 "Art. $1^{\circ}$ São atividades privativas de advocacia: I - a postulação a qualquer órgão do Poder Judiciário e aos juizados especiais". Estatuto da Advocacia e da OAB.

${ }^{7} \mathrm{O}$ advogado deve abster-se de "entender-se diretamente com a parte adversa que tenha patrono constituído, sem o assentimento deste". (Art. $2^{\circ}$, parágrafo único, VIII, e) do Código de Ética e Disciplina da OAB.
} 
sobre a análise de efetividade da defesa pública versus privada. Recentemente têm surgido trabalhos focados em responder essas questões. O trabalho de Rafael Godói (2019), por exemplo, aponta que defensores públicos têm mais sucesso em seus pleitos do que os defensores particulares. O mesmo resultado é encontrado no trabalho do colombiano Andrés Rengifo (2020) que, como forma de avaliar a implementação do sistema acusatorial na Colômbia, analisa indicadores de desempenho da defesa em audiências e conclui que a defesa pública é mais influente na decisão do juiz e mais ágil em responder à acusação. Ainda assim, Rengifo (2020) aponta que a defesa, independentemente do tipo, tem sua qualidade prejudicada por diversos fatores que dificultariam sua atuação, como, por exemplo, o custoso contato com a parte a ser defendida ou ainda a articulação entre juízes e promotores.

A capacidade da defesa contestar a acusação pode ser um fator chave para compreender a condenação por tráfico de drogas. Para isso, é importante considerar que o processo penal pode ser orientado tanto por princípios inquisitoriais quanto por acusatoriais. Enquanto o modelo inquisitorial busca a "verdade real" sobre os fatos, perseguida pela polícia e aproveitada pelo órgão de acusação, o modelo acusatorial, mais do que uma história única minimamente coerente sobre o delito, tem por enfoque a produção de provas e o debate sobre elas, em pleno contraditório. Assim, num modelo inquisitorial, caberia à defesa propor uma "versão mais convincente" sobre o delito, enquanto que, no modelo acusatorial, a defesa teria o papel de produzir e contestar provas perante o juízo.

Para Kant de Lima (2008), embora formalmente o Brasil adote o modelo acusatorial após o oferecimento da da denúncia, a investigação realizada pela polícia, sem o contraditório, contaminaria todo o processo. Isso porque as evidências produzidas durante o inquérito seriam aproveitadas na denúncia e posteriormente, mesmo quando judicializadas, norteariam a formação do convencimento do juiz. Desse modo, o processo penal no Brasil, de um modo geral, seria norteado por princípios inquisitoriais, cabendo à defesa contestar a versão policial dos fatos.

Os trabalhos de Lemgruber e Fernandes (2015) e Jesus et al (2011), ressaltam que, ao invés de ampla defesa, existe uma ampla acusação, sendo que a defesa técnica tem mostrado pouca capacidade de contradizer a versão policial sobre o crime, pois tais profissionais gozam de fé pública e tem ampla discricionariedade, sobretudo em determinar quem é o traficante e o usuário no caso da incriminação pelo delito de tráfico de drogas. 
Ademais, mesmo que formalmente haja o exercício do direito de defesa em fase policial, isso não significa que o indiciado poderia contestar a versão policial dos fatos, pois, nesta fase, em especial nas audiências de custódia, não cabe à defesa arguir sobre questões de mérito, ou seja, de contestar a versão policial sobre os fatos (LAGES, 2020). Desse modo, quando a polícia indicia alguém por tráfico de drogas, há, nessa fase, pouco espaço para a defesa contradizer os apontamentos da versão policial. Assim, mesmo que formalmente exista o direito à defesa, o peso dos registros policiais seriam tão fortes que impediriam a sua contestação ao longo do processo penal, mesmo após o oferecimento da denúncia.

Resta analisar se essa capacidade de contradizer a acusação muda conforme o tipo de defesa seja pública ou particular. Essa capacidade, além do caráter inquisitorial ou acusatorial do processo, pode variar a depender da interação entre a defesa com os demais membros da corte. Machado e Oliveira (2017), em seu trabalho de revisão da literatura acerca do fluxo do SJC, constataram que, em uma justiça já considerada lenta, o defensor, juntamente com os outros atores do processo, deve contribuir para a eficiência do sistema e, para tanto, mesmo que deixe de atender ao melhor interesse do seu cliente, deve se esforçar para diminuir a morosidade do processo.

O trabalho de Blumberg (1973) reforça essa atuação que visa buscar um acordo entre as partes, acelerar o andamento processual e ainda, manter boas relações com o judiciário e a promotoria; já que, enquanto a relação com o cliente é passageira, a relação com os colegas de trabalho, não é. Assim, o advogado ou defensor tem que compatibilizar o melhor interesse do seu cliente com os interesses dos outros atores do SJC, como a rápida tramitação do caso, sob pena de perder o seu bom relacionamento com os outros operadores do sistema. De acordo com Sapori (1995), a defesa tende a abrir mão do seu dever com o cliente, tendo como prioridade manter o funcionamento de uma burocracia informal, a fim de permitir que o processo tenha um bom andamento no fluxo da justiça. Assim, ele não perpetua uma fama ruim no ambiente do tribunal.

Mesmo com esse esforço da defesa apontado por Sapori, Izabel Nuñez (2018), em sua tese de doutorado com base em pesquisa etnográfica, notou a formação de um parentesco simbólico entre defensor público, promotor de justiça e juiz. De acordo com Nuñez, mesmo estabelecendo funções antagônicas e "brigando" no tribunal, estes operadores criam regras informais de etiqueta que regulam o andamento das audiências. A partir da prestação de favores e da criação de obrigações e lealdades, vivem numa espécie de família, com fortes relações 
pessoais. Para a autora, como os advogados particulares não partilham o vínculo com o Estado e não dominam tais regras, eles não pertencem a essa família judicial; o que tem consequências práticas para a sua atuação, já que muitas vezes são vistos como inconvenientes e não confiáveis.

A partir da literatura levantada, vimos que a prática da defesa varia de acordo com os princípios que norteiam o processo penal, seja o princípio acusatorial, em que o seu papel é a produção de provas em contraditório, seja inquisitorial, em que deve apresentar uma versão mais convincente sobre o delito, o que é tarefa bastante difícil de se fazer, sobretudo após a elaboração do inquérito por agentes que gozam de fé pública (KANT DE LIMA, 2010). Ademais, o exercício da defesa, na prática, nem sempre tem em vista o melhor interesse do cliente, mas também busca a preservação das relações de trabalho com os outros operadores (BLUMBERG, 1973), ou seja, prepondera o "melhor interesse do Estado". Nestas relações, não apenas formais mas também informais, Nuñez (2018) chama a atenção para a ideia de "família judicial", a qual, na maioria das vezes, não integra o advogado particular, que passa a ser visto como "estranho" na corte.

A partir desse panorama, este artigo propõe uma análise qualitativa e quantitativa do exercício da defesa nos processos de tráfico de drogas. Se existe uma diferença na atuação de um advogado particular ou um defensor público, até que ponto ela muda o curso do processo e o relacionamento com o cliente e com o tribunal? A partir dessas questões, será analisada se realmente "a defesa é indispensável à administração da justiça"ou se é um papel meramente cerimonial. A seguir, a metodologia do trabalho será descrita.

\section{METODOLOGIA}

Este artigo é fruto da pesquisa intitulada "Fluxo do Processo de Tráfico de Drogas em Belo Horizonte", financiada pelo CNPq e realizada pelos pesquisadores do Centro de Estudos em Criminalidade e Segurança Pública (CRISP) da Universidade Federal de Minas Gerais (UFMG), que seguiu a metodologia de fluxo longitudinal retrospectivo. De acordo com Vargas e Ribeiro (2008), a pesquisa longitudinal retrospectiva consiste na reconstituição das ocorrências criminais de trás para frente. A partir da análise dos casos já encerrados, é feita a 
reconstituição do crime desde o seu registro até o seu desfecho no SJC. O formato longitudinal retrospectivo, embora apresente limitações, sobretudo no que tange à impossibilidade de análise dos casos que não chegaram até a fase da sentença, é uma metodologia adequada para o estudo em profundidade do tempo e das características dos processos criminais.

Para a consecução da pesquisa, o Tribunal de Justiça de Minas Gerais (TJMG) cedeu aos pesquisadores um espelho de todos os casos de tráfico de drogas encerrados entre 2007 e 2017 e, a partir deles, foi construída uma amostra de processos penais representativa por ano. O TJMG também permitiu a consulta aos autos processuais, a qual se deu no arquivo do tribunal. A consulta foi realizada a partir de dois formulários de pesquisa, um com vistas a produzir informações sobre o processo judicial e, o outro, sobre o perfil dos indiciados por tráfico de drogas e sobre as penalidades aplicadas. foram consultados 748 dos 15.246 processos de tráfico de drogas arquivados entre 2007 e $2017^{8}$ em Belo Horizonte, o que equivale a $5 \%$ do total. Nesses processos, 1495 pessoas foram denunciadas pela prática do crime em questão.

Neste artigo, foram focalizadas as seguintes variáveis: a presença de advogado durante a fase policial, a decisão na Audiência de Instrução e Julgamento, se houve ou não recurso e o tempo percorrido desde o oferecimento da denúncia até a data do trânsito em julgado da sentença. Esses dados foram cruzados com a espécie do defensor (público ou particular), para constatar se há ou não alguma relação com significância estatística entre essas variáveis. Toda essa análise foi realizada com a ajuda do "Statistical Package for Social Science" (SPSS), programa usado nas ciências sociais para análises estatísticas.

Além da aplicação dos formulários, também foram realizadas entrevistas com os operadores do direito que, diariamente, lidam com os processos de tráfico de drogas: três juízes, cinco promotores de justiça, cinco defensores públicos e um delegado de polícia. Ademais, a partir da consulta direta aos processos judiciais, foi possível fazer uma análise qualitativa acerca das diferenças de atuação entre a defesa pública e a privada, com destaque para as diferenças das peças processuais elaboradas pelos defensores públicos ou advogados particulares. Foram também acompanhadas 14 audiências de instrução e julgamento (AIJ), no Fórum Lafayette, em Belo Horizonte, com o intuito de observar e avaliar o trabalho da defesa "para além dos autos" e como é sua interação com os demais atores do SJC.

\footnotetext{
${ }^{8}$ Todos os casos pesquisaram consistiram em inquéritos que viraram processos judiciais, o que significa que chegaram a ser denunciados formalmente pelo Ministério Público.
} 
A seguir, os dados produzidos pela pesquisa serão apresentados e discutidos, a fim de apontar as eventuais diferenças entre a defesa pública e a privada no processamento do delito de tráfico de drogas, da investigação dos casos até o trânsito em julgado das decisões.

\section{RESULTADOS E DISCUSSÃO}

\section{$O$ início: quem entra como traficante no sistema de justiça e como o tipo de defesa interfere nesse processo?}

É primordial, antes de começar a análise do fluxo do processo de tráfico de drogas pelo tipo de defesa, entender o perfil de um dos principais atores desse processo: o acusado. Dos 1495 indiciados, $87 \%$ são do sexo masculino, $74 \%$ são pretos ou pardos ${ }^{9}, 62 \%$ jovens ${ }^{10}$ e $51 \%$ não possuem ensino fundamental completo. As pessoas processadas criminalmente correspondem ao perfil de quem é socialmente considerado como "bandido". Segundo Misse (2010), essa é uma categoria que não necessariamente diz respeito a quem praticou uma conduta criminosa, mas diz respeito a pessoas cuja própria existência - ser pobre, negro e com condições marginalizadas de vida - é relacionada à construção da ideia de periculosidade social. No que tange ao processamento do tráfico de drogas, esse perfil é bastante relevante, pois a prisão em flagrante, fruto do policiamento ostensivo, tem sido a principal estratégia das polícias para controlar o tráfico de drogas, em detrimento de uma investigação prévia e aprofundada sobre o delito (IPEA, 2015; CONECTAS, 2019).

Como consequência dessa predominância do policiamento ostensivo em detrimento do investigativo, em muitos casos o testemunho dos policiais configura-se como a única prova do crime, sendo determinante inclusive para a diferenciação entre as condutas de uso e de tráfico de drogas. Considerando que a legislação estabelece critérios amplos e subjetivos para a diferenciação dessas condutas, na prática, os policiais baseiam-se em determinados estereótipos sociais, o que teria por consequência o enquadramento massivo de pessoas pobres, negras,

\footnotetext{
9 Informações retiradas do boletim de ocorrência, de acordo com a identificação racial realizada pelo policial. Mesmo assim, em 10,3\% das situações, não havia informações sobre raça ou cor da pele do indivíduo abordado pela polícia.

${ }^{10}$ Idade igual ou inferior a 30 anos.
} 
flagradas com pouca quantidade de substâncias entorpecentes, como traficantes de drogas (BOITEUX, 2009; CAMPOS; ALVAREZ, 2017).

Caberia então à defesa, pública ou particular, resguardar os direitos dessas pessoas. Embora seja uma instituição com defasagem de recursos e déficit de pessoal, a defensoria pública atendeu 54\% (801 casos) dos réus da amostra, enquanto que os advogados particulares foram responsáveis por 36\% (542 casos). Em 4\% (57 casos) houve a atuação de advogados dativos e em 6\% (94 casos) não foi possível acessar os dados sobre a defesa da parte, de modo que no banco de dados consta sem informação. Assim, se de um lado grande parcela dos acusados confiaram sua causa a um advogado particular, por outro lado, os dados reforçam a relevância social da defensoria pública que assiste mais da metade dos acusados por tráfico de drogas. Para as análises aqui propostas, foram utilizados apenas os dados que envolvem a atuação de advogado particular ou de defensor público.

Ordinariamente, o processo penal se inicia com a denúncia do Ministério Público, após o término do inquérito policial, e acaba quando a sentença transita em julgado, isto é, quando mais nenhum recurso é cabível ${ }^{11}$. O tempo percorrido entre essas etapas é variável de acordo com vários fatores ${ }^{12}$ e supõe-se que a espécie de defesa (público ou privado) possa ser um deles. Todavia, é na fase pré-processual, ou seja, anterior a denúncia, em que os futuros réus são ouvidos pela primeira vez e em que é feito o exame toxicológico preliminar. Esses procedimentos são especialmente importantes nos casos de tráfico de drogas, como destacam Lemgruber e Fernandes (2015), pois determinam os rumos do processo, se será indiciado por uso ou tráfico de drogas. Mesmo sendo uma fase definidora do futuro dos investigados, muito raramente, durante a análise documental, foram encontrados casos em que o indiciado depôs na presença de um advogado, sendo que em todos esses raros casos tratava-se de um advogado particular. Assim, percebe-se um déficit do direito de defesa durante o inquérito policial, fase essa essencial para o curso do processo penal.

Como pode ser observado na tabela 01 a seguir, 87,9\% dos indiciados não possuíam assistência nesse momento inicial e crucial para um possível julgamento futuro. Apenas 10,6\% pagaram por essa assistência jurídica e não se obteve informação acerca de 22 indiciados. A

\footnotetext{
11 Vale ressaltar que a data do trânsito em julgado pode variar para cada indiciado de um mesmo processo, isso porque as determinações das sentenças são individualizadas e alguns réus se valem do recurso e outros não.

${ }^{12}$ Alguns observados durante a análise documental foram: o tipo penal do crime em questão, como foi a abertura do inquérito policial (se por portaria ou flagrante) e a quantidade de indivíduos envolvidos.
} 
interpretação desse resultado merece uma ressalva: como todos os processos analisados foram formalmente iniciados a partir da denúncia, não é possível fazer quaisquer considerações sobre os casos que não chegaram a ser denunciados. Com os dados produzidos, é possível apontar apenas que a maioria dos processos penais, em que a denúncia foi efetivada pelo Ministério Público, os investigados não contaram com assistência jurídica.

Tabela 1 - Houve presença de advogado ou defensor público durante a coleta do depoimento do suspeito do crime (fase policial) - processos de tráfico de drogas (Belo Horizonte - 2006 a 2016)

\begin{tabular}{lcc}
\hline Presença de advogado durante o depoimento policial & Frequência & Percentual \\
\hline Não & 1299 & 86,9 \\
Sim & 186 & 12,4 \\
Sem informação & 10 & 0,7 \\
Total & 1495 & 100 \\
\hline
\end{tabular}

Fonte: Pesquisa de tráfico de drogas

Mesmo que historicamente o inquérito policial seja sigiloso, a Constituição de 1988 garantiu o acesso de seu conteúdo pelo advogado. Porém, de acordo com D’Urso (1999, p. 2), "é muito comum, portanto, a Comissão de Prerrogativas da Ordem dos Advogados do Brasil, receber reclamações de advogados que foram impedidos, quer pela autoridade policial ou por algum agente de polícia, de examinar autos de inquérito policial na delegacia”. Ou seja, se a presença do advogado tem como finalidade a maior ciência do andamento da ocorrência, os dados da pesquisa que apontam para o baixo acesso à defesa técnica durante a fase policial está em consonância com a ideia de que ainda há empecilhos da prática da advocacia nas delegacias policiais.

\section{A partir da denúncia: como se diferenciam os tipos de defesa?}

É a partir do oferecimento da denúncia que a atuação do advogado ou defensor público se torna obrigatória. O juiz estipula um prazo de dez dias ${ }^{13}$ para o réu apresentar uma defesa escrita à acusação. Mesmo a lei determinando a nomeação de defensor público apenas se a

${ }^{13}$ Art. 55 da lei 11343/06: "Oferecida a denúncia, o juiz ordenará a notificação do acusado para oferecer defesa prévia, por escrito, no prazo de $10(\mathrm{dez})$ dias. $\S 3^{\circ} \mathrm{Se}$ a resposta não for apresentada no prazo, o juiz nomeará defensor para oferecê-la em 10 (dez) dias, concedendo-lhe vista dos autos no ato de nomeação". 
resposta não for feita no prazo por um advogado particular, muitas vezes o juiz já deixa nomeado um defensor público, para já adiantar a tramitação do feito. De acordo com o princípio do contraditório e da ampla defesa, deve ser garantido ao acusado o direito de conhecer o conteúdo da denúncia e pronunciar-se acerca de tudo o que for produzido contra ele (AVENA, 2018). No caso do tráfico de drogas, o juiz não pode dar andamento ao processo enquanto não houver a defesa prévia. A partir dessa fase, já podemos analisar algumas questões.

Nos processos analisados, os quais constavam com a denúncia aceita, foi percebido que, independentemente do tipo de defesa, o juiz apenas cita que houve a defesa escrita e em que folhas do processo se encontra, e então recebe a denúncia. Aparentemente, a defesa prévia apresenta-se como um ato formal do processo, que não é capaz de alterar a decisão judicial, já que esta não faz qualquer referência aos argumentos utilizados pela defesa e, de pronto, já aceita a denúncia. Também é perceptível, ao analisar o processo de tráfico de drogas, a necessidade de que essa defesa seja apresentada o mais rapidamente possível para que o fluxo seja mantido sem interrupções. Há casos observados em que, para um mesmo réu, há duas defesas prévias, uma da defensoria pública e outra do advogado particular. Isso acontece porque, normalmente, quando o advogado particular demora a juntar sua peça no processo, o juiz prontamente nomeia um defensor para que o faça, dando seguimento ao fluxo processual.

\section{A diferença simbólica: as páginas importam?}

É perceptível, ao analisar os processos físicos, quando a defesa prévia é de um defensor público em detrimento do privado, e não somente pelo logotipo no topo da página ou pela assinatura ao final. Advogados particulares tendem a elaborar peças processuais maiores, com um vocabulário mais apelativo ${ }^{14} \mathrm{e}$, em alguns casos, dão uma aparência única à sua peça com folhas estilizadas. Já os defensores públicos são mais sucintos e imediatos, sendo que muitas de suas defesas prévias não passam de uma página. Essas diferenças não representam nenhuma relação de superioridade entre as defesas, já que, como foi dito anteriormente, o conteúdo desse documento não parece influenciar o processo diretamente.

\footnotetext{
${ }^{14}$ Em várias peças de advogados particulares, há clemências religiosas e ainda apelo por justiça, escrevendo essa palavra em destaque.
} 
No acompanhamento de uma das audiências de instrução e julgamento, a defensora pública, durante uma conversa informal com o promotor, ilustrou bem a sua percepção sobre a defesa prévia na seguinte fala:

...já a defesa prévia é rápida. Apenas uma lauda. Só faço o pedido das testemunhas. Você não sabe, não é? Se alguma coisa vai mudar, se o réu vai decidir confessar... (Anotações de acompanhamento de audiências de tráfico de drogas, $3^{\text {a }}$ Vara de Tóxicos, defensora pública, 2019)

Supõe-se que um dos motivos para a defesa prévia do advogado particular ser mais desenvolvida seja o contato mais próximo com o cliente. Quando é defensor público, em muitos casos o primeiro contato entre o réu e seu advogado ocorre minutos antes do início da audiência de instrução e julgamento (AIJ) e, normalmente, o advogado particular tem um contato anterior e até mais próximo com o cliente ou seus familiares, podendo fazer uma defesa prévia mais consistente em seus pedidos. Isso é demonstrado pela fala de duas das defensoras entrevistadas, quando perguntadas sobre o que elas achavam da atuação da defensoria pública no tráfico de drogas:

\footnotetext{
"Diante disso que a gente vê aqui, apesar de termos até um retorno significativo de cartas dos familiares, as testemunhas praticamente, dos fatos, são muito raras e a gente trabalha realmente com a prova produzida pela polícia mesmo". (Entrevistada defensora 1, defensoria pública, 2018)

“(...) por exemplo, estou aqui com um processo para defesa prévia família não me procurou, eu não sei onde ele mora (...). Então, assim no ponto de conseguir acessar o réu e conseguir deles contraprovas da acusação acredito que a defensoria falhe." (Entrevistada defensora 2, defensoria pública, 2018)
}

A defesa prévia é apenas um dos muitos documentos produzidos pelo advogado no processo. Quando o réu está preso, é muito comum o pedido de habeas corpus, o que acontece em grande parte dos casos. Dos 748 processos, 706 foram de presos em flagrante e, desses, em 292 a prisão foi convertida em preventiva. Quando o advogado particular não faz o pedido de habeas corpus junto à defesa prévia, é até difícil percebê-lo diferente do defensor público. 
Além desses dois documentos, as aparições dos defensores (públicos e privados) se destacam nas alegações finais escritas, documento que pode ser considerado o mais importante do processo, pois antecede a definição da sentença do juiz e das razões e contrarrazões, nos casos dos processos que seguiram além da primeira instância. No que tange à diferença entre as defesas, nos processos analisados, as alegações finais feitas por advogados particulares eram bem mais longas, muitas vezes contavam com mais de quinze páginas.

Assim, as peças principais da defesa na primeira instância (defesa prévia e alegações finais), quando consideradas em sua forma, podem levar a crer que advogados particulares desempenham um papel mais relevante do que o da defensoria pública, pois o número de páginas poderia ser visto como um maior empenho ao caso. Porém, em uma justiça burocratizada, as peças processuais possuem receitas práticas que buscam agilizar o processo (Sapori, 1995) e a defesa não está excluída dessa forma de operação. A defensoria pública e a advocacia particular podem até seguir receitas diferentes na elaboração, mas a base é a mesma e o resultado final também. Se é permitido comparar, os advogados particulares se preocupam em servi-la num prato mais bonito para os juízes, promotores e seus clientes, enquanto não há essa preocupação no caso dos defensores públicos, já que eles não precisam de "marketing" para promover sua atuação.

Um documento processual, como qualquer estilo textual, possui um esqueleto que deve ser seguido. Porém, a preocupação de manter a rapidez no curso processual impede que sejam acrescentadas as particularidades do réu e do caso. $\mathrm{Na}$ análise documental, alguns erros foram evidentes. O mais grave de todos, em uma defesa prévia de um advogado particular, foi o nome do réu, que apesar de estar em negrito e letra maiúscula, não pertencia a nenhum dos indiciados no processo. Claro, num primeiro momento ponderou-se ser apenas um erro relacionado à não individualização da documentação, porém, com o acompanhamento das audiências, percebeuse que esse erro é justamente decorrente da exacerbada padronização da documentação que as defesas - públicas e privadas - apresentam no processo.

Durante o acompanhamento das AIJ's, percebeu-se que defensores públicos, em alguns casos, já estão com o computador elaborando as alegações finais ${ }^{15}$, modificando apenas alguns pontos do documento já pronto - provavelmente, utilizado em outro caso semelhante. Esse fator

\footnotetext{
${ }^{15}$ Notamos que essa elaboração prévia à AIJ é também feita por juízes, no caso das sentenças, ou promotores, para alegações finais.
} 
é justificado pelos defensores que, por terem uma grande quantidade de casos para atender, procuram se adiantar ao máximo para cumprir a demanda. Entretanto, numa audiência acompanhada na $10^{\mathrm{a}}$ Vara Criminal em 2019, em que a tipificação penal era roubo, o defensor entregou, antes da audiência começar, as suas alegações finais salvas em um pen-drive para o escrevente, demonstrando o quão teatral pode ser o papel da audiência não só para o juiz e o promotor, mas também para a defesa, já que as alegações finais já estavam prontas antes mesmo das provas serem produzidas em contraditório. Do outro lado, não houve nenhum advogado particular que entregou suas alegações finais no mesmo momento da AIJ, seja no início ou no final. Em uma audiência (1 ${ }^{\mathrm{a}}$ Vara Criminal, 2019), o advogado particular pediu um prazo de vinte e quatro horas para entregar as alegações finais e o juiz insistiu para que ele entregasse naquele dia, afirmando que "se você fizer agora já sentencio rapidinho".

Isto posto, e pelas alegações dos defensores entrevistados, salientamos que a defesa pública possui maior dificuldade em individualizar os casos, tanto em razão da quantidade maior de processos a serem despachados, quanto pelo baixo contato com o réu e seus familiares. Por outro lado, as peças produzidas pela defesa privada, sendo mais longas e apelativas, podem fugir às regras informais e de eficiência da família judicial. Essa característica, entretanto, perde valor ao considerar a justiça como uma linha de montagem, a qual, ao invés de se preocupar com o conteúdo, demanda mais a presença da documentação completa para seguir o seu fluxo sem gargalos. Resumindo, existem diferenças na produção das peças processuais a depender do tipo de defensor, mas essas diferenças não parecem contribuir para a maior efetividade da defesa. Então o que realmente um advogado - público ou particular - pode fazer para manipular o processo de alguma forma, garantindo um resultado final mais benéfico a seu cliente?

\section{A sentença do juiz: faz diferença quem defendeu o réu?}

O maior interesse do réu é conseguir uma sentença a seu favor, de preferência a absolvição. Como indicam as pesquisas com sujeitos encarcerados, vários acreditam que uma defesa particular alcançará esse resultado favorável mais facilmente (GODÓI, 2019). Entretanto, como pode ser analisado no gráfico abaixo, não há discrepâncias na porcentagem de condenações de acordo com o tipo da defesa. Enquanto 29,0\% dos processos em que atuaram advogados particulares terminaram com uma sentença absolutória, 31,3\% dos processos com 
defesa pública terminaram com a mesma decisão. De fato, quando cruzamos a espécie de defesa com a sentença do juiz, a diferença entre defesa privada ou pública, com 95\% de confiança, não é estatisticamente significativa.

\section{Gráfico 1 - Sentença final da AIJ por tipo de defensa - processos de tráfico de drogas (Belo Horizonte - 2006 a 2016)}

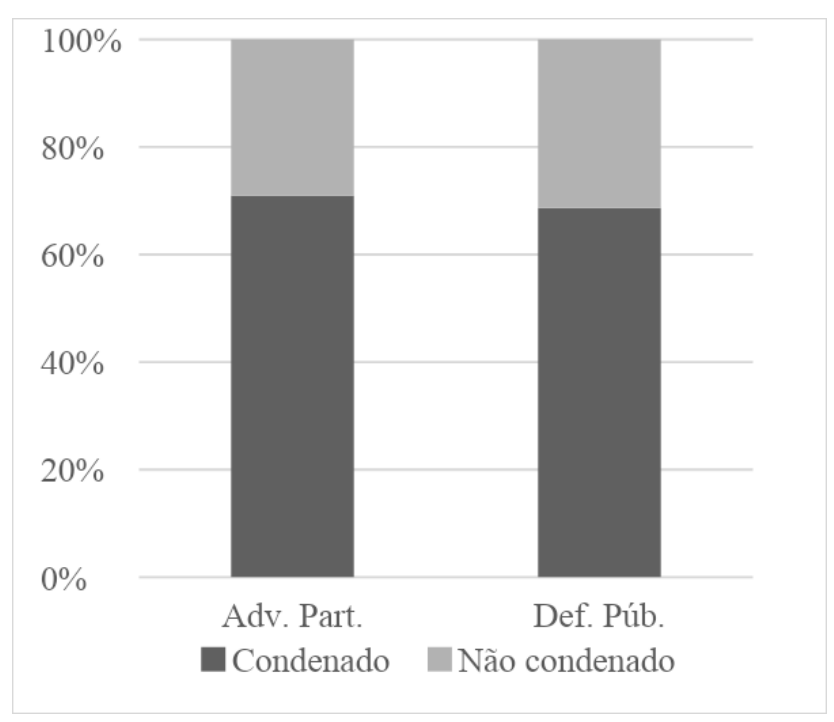

Fonte: Pesquisa de tráfico de drogas

Pesquisas como o relatório do Instituto de Defesa do Direito de Defesa (IDDD) sobre audiências de custódia no território nacional apontam que 85,5\% das decisões judiciais convergem com o pedido do Ministério Público e apenas 6,69\% com pedidos da defesa. $\mathrm{Na}$ base de dados da pesquisa do tráfico de drogas (CRISP/UFMG), ora em análise, considerando apenas os casos válidos, isto é, excluindo os casos sem informação, quando cruzado os dados da sentença resultantes em absolvição e o pedido do MP também para absolvição do réu (tabela 2), há associação estatisticamente significativa entre os dois $(P=0,000)$. Assim, a decisão da sentença é, muitas vezes, alheia à defesa - pública ou privada, valendo-se apenas da visão do Ministério Público, que é ratificada nas sentenças. 


\section{Tabela 2 - Pedido do Ministério Público X Sentença - processos de tráfico de drogas (Belo Horizonte - 2006 a 2016)}

\begin{tabular}{|c|c|c|c|c|c|c|c|c|}
\hline \multirow[b]{3}{*}{ O MP pediu absolvição? } & \multicolumn{8}{|c|}{ Sentença } \\
\hline & \multicolumn{2}{|c|}{ Absolvição } & \multicolumn{2}{|c|}{ Condenação } & \multicolumn{2}{|c|}{ Desclassificação } & \multicolumn{2}{|c|}{ Total } \\
\hline & $\mathrm{N}$ & $\%$ & $\mathrm{~N}$ & $\%$ & $\mathrm{~N}$ & $\%$ & $\mathrm{~N}$ & $\%$ \\
\hline Não & 164 & $62 \%$ & 828 & $95 \%$ & 181 & $93 \%$ & 1173 & $89 \%$ \\
\hline Sim & 99 & $38 \%$ & 29 & $5 \%$ & 10 & $7 \%$ & 138 & $11 \%$ \\
\hline Total & 263 & $100 \%$ & 859 & $100 \%$ & 191 & $100 \%$ & 1269 & $100 \%$ \\
\hline
\end{tabular}

Ainda que a sentença seja o principal foco da defesa, há outras formas que um advogado pode influenciar o processo e tentar alcançar um panorama mais favorável ao réu. De acordo com Sapori (1995, p. 2), “(...) em diversas situações seu interesse [do advogado] é retardar o fluxo dos processos penais" utilizando de estratégias para a prescrição do feito. Isso é, para que o prazo do processo na fase jurídica, desde a denúncia até o trânsito em julgado, atinja ou ultrapasse o limite de tempo previsto no art. 109 do Código Penal ${ }^{16}$, sendo assim extinta a punibilidade. Essa é uma ideia que percorre todo o fórum.

Durante várias audiências, em conversas informais entre juiz, promotor e defensor, foi comum ouvir esse tipo de crítica aos advogados particulares. No intervalo entre duas audiências, um promotor, ao discutir as pautas da semana com outro promotor, lamentou por ter de atuar em um caso de gangue, alegando que, nesses casos, eles contratam advogados particulares que ficam postergando o processo, afirmando que "a gente toma pancada do crime organizado, toma demais" (11 ${ }^{\text {a }}$ Vara Criminal, 2019).

Tendo isso em vista, a partir da análise dos processos de tráfico, comparou-se as médias do tempo de duração do processo (desde o oferecimento da denúncia até a data de trânsito em julgado) de cada tipo de defensor, resultando nas tabelas abaixo:

\footnotetext{
${ }^{16}$ Art. 109 da lei 2848/40 do CP. "A prescrição, antes de transitar em julgado a sentença final, salvo o disposto no $\S 10$ do art. 110 deste Código, regula-se pelo máximo da pena privativa de liberdade cominada ao crime, verificando-se: I - em vinte anos, se o máximo da pena é superior a doze; II - em dezesseis anos, se o máximo da pena é superior a oito anos e não excede a doze; III - em doze anos, se o máximo da pena é superior a quatro anos e não excede a oito; IV - em oito anos, se o máximo da pena é superior a dois anos e não excede a quatro; V - em quatro anos, se o máximo da pena é igual a um ano ou, sendo superior, não excede a dois; VI - em dois anos, se o máximo da pena é inferior a um ano; VI - em 3 (três) anos, se o máximo da pena é inferior a 1 (um) ano."
} 
Tabela 3 - Média (em dias) do tempo de processamento por espécie de defensor - processos de tráfico de drogas (Belo Horizonte - 2006 a 2016)

\begin{tabular}{lrrr}
\hline Tipo de defesa & Número de casos & Média de tempo & Desvio Padrão \\
\hline Advogado Particular & 487 & 730,9 & 442,1 \\
Defensor Público & 741 & 741,8 & 458,3 \\
Total & 1228 & 737,5 & 451,8 \\
\hline \multicolumn{4}{r}{} \\
\end{tabular}

Considerando os dados válidos sobre o tempo de processamento dos casos, observamos que não há relevância significativa entre o tipo de defesa e o tempo médio de duração do processo. Ao contrário do esperado, a média dos advogados particulares (642 dias) foi menor do que a dos defensores públicos (653 dias). O teste Anova, com valor de significância superior a 0,050 , indica que a diferença não é estatisticamente significativa com $95 \%$ de confiança.

O trabalho de Godoi (2019) sobre a defesa pública afirma que a defensoria é uma das engrenagens que mantém a justiça em linha de montagem. De acordo com os resultados apresentados na Tabela 2, podemos considerar que a defesa em geral, incluindo a privada, é submetida à burocratização do SJC e às demandas de eficiência. Mesmo assim, o réu acredita que será melhor representado judicialmente ao contratar um advogado particular, porque, teoricamente, ele combateria essa burocratização em busca de melhores resultados. Uma conversa entre o réu e o juiz durante uma audiência na $1^{\circ}$ Vara de Tóxicos ilustra bem essa ideia:

Réu: sou pobre, não posso nem pagar um advogado e tenho que ser defendido pelo (defensor) público.

Juiz: Não é porque você não paga que é de graça. Tenha certeza de que você está sendo muito bem assistido.

(Anotações de acompanhamento de audiências de tráfico de drogas, $1^{\mathrm{a}}$ Vara de Tóxicos, 2019)

Como pode ser observado pela argumentação do juiz em favor da Defensoria Pública, o processo penal nem sempre é visto como uma rivalidade entre os operadores do Direito, os 
quais, inclusive, podem ser unidos por vínculos que se aproximam da ideia de família judicial (Nuñez, 2018). É interessante observar, ainda, as tentativas (frustradas ou não) dos advogados integrarem essa família, mesmo que em detrimento do melhor interesse para o cliente. De modo a manter uma relação mais próxima com juiz e promotor, o advogado particular, quando o réu não estava presente na sala, chegou até a falar mal do seu cliente:

Esse é daquele que fica enchendo o saco. Estou sendo pago, tenho que aguentar. (Anotações de acompanhamento de audiências de roubo, $1^{\mathrm{a}}$ Vara Criminal, 2019, advogado particular).

No que tange ao pedido de recurso, também não foi observada diferença entre a atuação do advogado particular e da defensoria pública. A partir da tabela 3, em que foram considerados os casos com dados válidos sobre a existência de recurso, observa-se que não há significância estatística (significância do teste qui-quadrado maior que 0,05 ) no cruzamento entre ter ou não apelação e o tipo de defensor. Assim, não é o defensor público quem aceita mais facilmente a sentença do juiz e nem o advogado particular quem insistirá mais a favor do réu.

Tabela 3 - Processos em que houve apelação por tipo de defensor - - processos de tráfico de drogas (Belo Horizonte - 2006 a 2016)

\begin{tabular}{|c|c|c|c|c|c|c|c|c|}
\hline \multirow{3}{*}{$\begin{array}{c}\text { Houve } \\
\text { apelação? }\end{array}$} & \multicolumn{6}{|c|}{ Tipo de defensor } & \multirow{2}{*}{\multicolumn{2}{|c|}{ Total }} \\
\hline & \multicolumn{3}{|c|}{ Advogado Particular } & \multicolumn{3}{|c|}{ Defensor Público } & & \\
\hline & $\mathbf{N}$ & $\%$ & & & $\%$ & & & \\
\hline Não & & & $30 \%$ & 250 & & $31 \%$ & 411 & $31 \%$ \\
\hline Sim & & & $70 \%$ & 552 & & $69 \%$ & 933 & $69 \%$ \\
\hline Total & & & $100 \%$ & 802 & & $100 \%$ & 1344 & $100 \%$ \\
\hline
\end{tabular}

Fonte: Pesquisa de tráfico de drogas

Portanto, os dados quantitativos e qualitativos da pesquisa contradizem a hipótese de que a espécie da defesa influencia o curso do processo penal. Em um sistema judicial tão burocratizado como o brasileiro, “os direitos ao contraditório e à ampla defesa não parecem muito mais do que a introdução de um mecanismo interno de redução de danos, um dispositivo 
que expulsa, dentro de um aparelho de captura" (GODOI, 2019). Ou seja, a defesa está submetida à estrutura em linha de montagem do sistema de justiça criminal, cabendo a ela apenas arranjar algumas fugas rápidas, como pequenas concessões ao réu, mas não tendo grande influência no rumo final do processo.

Se pensarmos na ideia de família judicial, Nuñez (2018) ressalta que, como toda "família", há valores comuns e hierarquias entre seus membros. Em nossa pesquisa, observamos que o defensor pode até integrar esse núcleo familiar, por ter um vínculo com o Estado e ter maior familiaridade com as regras informais que norteiam o andamento dos trabalhos. Porém, se aproxima do advogado particular em termos de sucesso de seus pleitos. Assim, o defensor público se assemelha aqui ao "primo pobre" da família e o juiz tende a refletir em sua decisão os pedidos do promotor de justiça - seja o caso assistido por advogado público ou particular.

Dessa forma, os valores defendidos por essa família judicial, ou a sua sensibilidade jurídica, nas palavras de Kant de Lima (2010), se alicerçam sobremaneira nos princípios inquisitoriais e na cultura cartorial. Prevalece, assim, aquilo que está "reduzido a termo" no inquérito policial, que é posteriormente reproduzido na denúncia como "verdade" dos fatos, que, depois, é ratificada na sentença. Nesse ethos inquisitorial, supõe-se que o réu sempre mente para defender-se, o que macula suas alegações e as de seu defensor - independente se público ou privado - que não coincidirem com aquilo já investigado previamente pela polícia (KANT DE LIMA, 2010).

\section{CONSIDERAÇÕES FINAIS}

Como Misse (2010) aponta, o "tipo social” do indivíduo pode ser mais relevante para a sua incriminação no SJC do que o "tipo penal" eventualmente praticado, pois determinados sujeitos já são previamente julgados como "bandidos", e isso acontece especialmente no tráfico de drogas, que tem sido manejado sobretudo pela prisão em flagrante pela Polícia Militar, que goza de ampla discricionariedade para abordar os sujeitos e classificar as condutas como uso ou como tráfico de entorpecentes. Assim, antes mesmo da denúncia, determinadas pessoas são o alvo preferencial da polícia, e, posteriormente, os resultados deste trabalho indicam que o 
exercício da defesa, seja pública ou particular, não tem sido capaz de influenciar a decisão judicial.

Essa ausência de diferenças entre a defesa pública e privada no processo de sentenciamento indica que o sistema não concede tratamento desigual entre quem pode ou não pagar por um advogado, de modo que o tipo de defesa, a princípio, não teria significância no desfecho do caso. Porém, observamos que a sentença judicial tende a acolher sobretudo os pedidos do Ministério Público, o que mostra que, na verdade, a defesa do indiciado, em si, é que tem pouca capacidade de influenciar na decisão. Assim, no modelo proposto de família judicial (NUNEZ, 2018), a pesquisa aponta para a predominância de valores morais de base inquisitorial, de modo que, mesmos se a defesa é exercida por um membro da família, na prática, as alegações que contradizem a versão oficial do inquérito não são consideradas.

No que tange às limitações do estudo, é importante ressaltar que este trabalho não pretendeu ser exaustivo sobre os elementos que diferenciam a defesa particular e pública. Por mais que o tipo de defesa não tenha mostrado influência considerável na decisão de condenação ou absolvição do tráfico de drogas, são necessários novos estudos para, ao menos, entender se o tipo de defesa interfere na pena recebida, tornando a pena mais branda, ou se, ao longo do processo, conseguem benefícios para o réu, como a liberdade provisória. Ademais, o estudo se limitou ao processo de tráfico de drogas, não incluindo em sua análise a prática de escritórios de advocacia renomados, que são inacessíveis à maior parte dos indiciados por esse delito. Então, nos processos analisados, o Ministério Público, ao reproduzir a versão oficial do inquérito, produzida por agentes que gozam de fé pública, ganha predominância e tem seus pedidos acatados em quase todos os casos, tornando assim a atuação da defesa meramente cerimonial.

\section{REFERÊNCIAS BIBLIOGRÁFICAS}

AVENA, N. Processo Penal. 10ª ed. São Paulo: Método, 2018. cap. 1, p. 3-49. Bíblia Sagrada. São Paulo: Paulinas Editora, 2005.

BLUMBERG, A. S. The Practise of Law as Confidence Game: organizational cooptation of a profession. Law and society review, p. 15-39, 1967. 
BRASIL, Código de Ética e Disciplina da OAB, de 13 de fevereiro de 1995. São Paulo: Primeira Impressão, 2002.

BRASIL, Lei n. 11719/2008 - Código de Processo Penal. Disponível em: <http://www.planalto.gov.br/ccivil_03/_Ato2007-2010/2008/Lei/L11719.htm>. Acesso em: 13/06/2020.

BRASIL, Lei n. 2484/1940 - Código Penal. Disponível em : <http://www.planalto.gov.br/ccivil_03/decreto-lei/del2848compilado.htm>. Acesso em: 06/08/2020.

BRASIL. Lei n. 8096/1994 - Estatuto da Advocacia e da OAB. São Paulo: Atlas, 2002.

BONFIM, E. M. Curso de processo penal. 4 ed. São Paulo: Saraiva, 2009.

BOITEUX, L., et al. "Tráfico de drogas e Constituição". Relatório de pesquisa. Pensando o Direito, vol. 12, n 2, p. 2013. Brasília: Ministério da Justiça, 2009.

CAMPOS, M. S; ALVAREZ, M. C. Pela metade: implicações do dispositivo médico-criminal da "nova" Lei de Drogas na cidade de São Paulo. Tempo Social, v. 29, n. 2, p. 45-74, 2017.

CONECTAS. Prisão a qualquer custo: como o sistema de Justiça descumpre decisão do STF sobre penas para pequenos traficantes. São Paulo: CONECTAS, 2020. Disponível em: <https://www.conectas.org/publicacoes/download/prisao-a-qualquer-custo-como-o-sistemade-justica-descumpre-decisao-do-stf-sobre-penas-para-pequenos-traficantes $>$, acesso em 02 de março de 2021.

CUNHA, S. S. de. História da advocacia no Brasil. Potsdam, 2005.

D'URSO, L. F. B. O sigilo no inquérito policial e o exame dos autos por advogado. Revista do Instituto de Pesquisas e Estudos. Bauru, n. 24, p. 169-180, dez./mar. 1998/1999.

GODOI, R. A arte de livrar: notas etnográficas sobre a defesa judicial pública no sistema de justiça criminal comum. Revista Brasileira de Segurança Pública. São Paulo, v. 13, n. 1, p. 140-156, fev./mar. 2019.

INSTITUTO DE DEFESA DO DIREITO DE DEFESA. O fim da liberdade: a urgência de recuperar o sentido e a efetividade das audiências de custódia. Relatório de pesquisa. São Paulo, 2019.

JESUS, M.G.M.d; OI, A.H; ROCHA, T.T.d; LAGATTA, P. Prisão Provisória e Lei de Drogas: um estudo sobre os flagrantes de tráfico de drogas na cidade de São Paulo. São Paulo, 2011.

KANT DE LIMA, R. "Cultura Jurídica e Práticas Policiais: A Tradição Inquisitorial”. In Kant de Lima, Ensaios de Antropologia e de Direito. Lumen Juris Editora. Rio de Janeiro, 2008.

KANT DE LIMA, R. "Sensibilidades jurídicas, saber e poder: bases culturais de alguns aspectos do direito brasileiro em uma perspectiva comparada". Anuário Antropológico, n. 2 :25-51, 2010. 
LAGES, L. "O sistema acusatório diante da prisão em flagrante: como o direito à defesa é exercido em fase de audiência de custódia?" Revista Brasileira de Segurança Pública, v.14, n.1, 2020.

LEMGRUBER, J; FERNANDES, M. Tráfico de drogas na cidade do Rio de Janeiro: prisão provisória e direito de defesa. Boletim Segurança e Cidadania. Rio de Janeiro, n. 17, p. 3-25, nov. 2015.

LÔBO, P. Comentários ao Estatuto da Advocacia e da OAB. 10 ed. São Paulo : Saraiva, 2017.

MACHADO, Bruno Amaral; OLIVEIRA, Marcus Vinicius Berno N de. O fluxo do sistema de justiça como técnica de pesquisa no campo da segurança pública. Revista Direito e Práxis. Rio de Janeiro, vol. 9, n. 2, 2018.

MOREIRA, T. M. Q. A constitucionalização da defensoria pública: dsputas por espaço no Sistema de Justiça. Opinião Pública, Campinas, vol 23, n. 3, 2017.

MISSE, M. Crime, sujeito e sujeição criminal: aspectos de uma contribuição analítica sobre a categoria "bandido". Lua Nova. São Paulo, n 79, p. 15-38, 2010.

NUÑEZ, I. "Aqui não é casa de vingança, é casa de justiça!": moralidades, hierarquizações e desigualdades na administração de conflitos do tribunal do júri da comarca do Rio de Janeiro. Tese de doutorado em Antropologia. Universidade Federal Fluminense, 2018.

ORIGEM, história da assistência jurídica e da defensoria pública. Disponível em: <www.dhnet.org.br/3exec/defensoria/defensoria1.html>. Acesso em: 30/05/2019.

PAIVA, M. A. L. A supremacia do advogado em face do jus postulandi. Revista de Informação Legislativa, Brasília, a.36, n. 141, p. 201-216, jan./mar. 1999.

RENGIFO, A. F; Marmolejo, L. Acción y representación: indicadores de desempeño de la defensa en una muestra de audiencias de control de garantías en Colombia. Latin American Law Review, n. 04, p. 1-23, 2020.

SAPORI, L. F. A administração da justiça criminal numa área metropolitana. Revista Brasileira de Ciências Sociais, 10(29), 143-157, 1995. 